\title{
Cross-disciplinary collaboration versus coexistence in LIS serials: analysis of authorship affiliations in four European countries
}

\author{
Cristóbal Urbano $^{1}$ (D) Jordi Ardanuy ${ }^{1}$ (i)
}

Received: 24 November 2019 / Published online: 19 April 2020

(c) The Author(s) 2020

\begin{abstract}
The interdisciplinary nature of library and information science (LIS) research has been highlighted for some time now. The term "interdisciplinary" is used primarily in the LIS literature as a general concept with different meanings that refer either to the coexistence of researchers from different scientific fields or to cross-disciplinary collaboration expressed in the form of coauthorship. This study analyses the disciplinary profile of LIS researchers with a view to ascertaining the actual level of cross-disciplinary collaboration and identifying all fields involved. Because of the complexity of identifying accurate affiliations at knowledge area level, the study was limited to authors from France, Germany, Spain and the UK. This analysis of authorship affiliation was performed based on research published in LIS serial titles indexed in Scopus during the 2010-2017 period. A rigorous and laborious process of identifying author affiliations was carried out. This involved checking the authorship of each paper and complementing this with information from websites, scientific social networks and other research endeavours whenever ambiguous situations arose. We observed that LIS departments produce barely a third of the research published in serial titles in the LIS subject category. Cross-disciplinary collaboration among all of the scientific fields involved is low, and even lower in LIS than in other fields. The low level of cross-disciplinary collaboration in LIS contradicts the interdisciplinary nature of LIS highlighted in the literature.
\end{abstract}

Keywords Authorship analysis · Coauthorship analysis · Cross-disciplinary collaboration analysis · Interdisciplinarity $\cdot$ Multidisciplinarity $\cdot$ Library and information science $\cdot$ Scopus $\cdot$ SJR $\cdot$ France $\cdot$ Germany $\cdot$ Spain $\cdot$ United Kingdom

Electronic supplementary material The online version of this article (https://doi.org/10.1007/s1119 2-020-03471-z) contains supplementary material, which is available to authorized users.

Cristóbal Urbano

urbano@ub.edu

1 Departament de Biblioteconomia, Documentació i Comunicació Audiovisual \& Centre de Recerca en Informació, Comunicació i Cultura (CRICC), Universitat de Barcelona, Melcior de Palau 140, 08014 Barcelona, Spain 


\section{Introduction}

The highly interdisciplinary nature of library and information science research (hereinafter, LIS) and the eclectic epistemological foundations of the LIS field of knowledge have been highlighted for some time now. For years, there has been debate concerning the existence of at least two subfields within LIS - that is, library science and information scienceand also the relationship between these two subfields, their relationship with other fields and even the name of the discipline (Buckland 1996; Cronin 2008; Holland 2008; Gunawardena et al. 2010; Ingwersen 1992; Nakano et al. 2018; Prebor 2010; Saracevic 1995; Shera 1968; Vakkari 1994).

Bates (1999) describes information science studies as a meta-field, like other information-based professions such as education, journalism and communication, albeit with logical differences in the methodologies and skills required. A similar opinion on the diversity of the epistemological focus of LIS is held by Saracevic (1999), who warns against the possible division of LIS into two isolated areas-one focused on technological systems, developed mainly by computer professionals, and the other devoted to research on information use and users. In his description and holistic characterization of LIS, Hjørland (2000) identifies three different "cultures" within this area: the first group is made up of teachers whose disciplinary identity is based mainly on the development of technical or management solutions in information processes and services; the second group, which he calls "the culturalists", have little commitment to developing the field as a discipline with its own identity and identify themselves with the generic disciplinary framework of the humanities and social sciences; and finally, the third, less numerous group, which he calls "the scientists", engage in library science, documentation and information as a research field in its own right. In other words, the use of the word interdisciplinary often responds to the need to describe a heterogeneous disciplinary reality, which is characterized by the presence under the same organizational units of individuals who understand the discipline quite differently.

In any case, it is clear that the interdisciplinary nature of LIS is subject to broad and indistinct interpretations, because it can be linked to all manner of scientific influences, exchanges and collaborations between disciplines. Most of the authors we have cited in previous paragraphs use the term interdisciplinary in a rather general sense, without clearly discriminating between the different levels of collaboration or integration between the authors who publish in the field. In fact, researchers who have studied interdisciplinarity (Holbrook 2013; Huutoniemi et al. 2010; Jacobs and Frickel 2009; Klein 1990, 2017) agree that there is no clear consensus on the definition of the term, such that it may be used in the literature to specifically identify collaborative work between disciplines, as well as a generic term to refer to any type of scientific exchange, coexistence in a set of subjectspecific publications or cross-disciplinary collaboration.

Actually, the definition endorsed by a cornerstone OECD report from 1972, that still has a great influence in the debate about the term "interdisciplinary", aligns with that more generic meaning: "An adjective describing the interaction among two or more different disciplines. This interaction may range from simple communication of ideas to the mutual integration of organizing concepts, methodology, procedures, epistemology, terminology, data, and organisation of research and education in a fairly large field." (Apostel et al. 1972, p. 25). However, as Klein (2017) or Holbrook (2013) remark, under that general meaning for the adjective "interdisciplinary" we can trace, at least, three specific types of collaboration depending on the type and intensity of relationship between the disciplines 
involved: multidisciplinary, for cases of juxtaposition, alignment and coordination of work from the positions of each discipline; interdisciplinary, for cases of integration, blending and linking; and transdisciplinary, for cases in which the disciplines of the participating collaborators are transcended, transgressed or transformed.

These specific terms and meanings should be carefully taken into account when reading the literature: most of the authors use the word interdisciplinary in a general sense, but the integration of disciplinary theory and methods required for real specific interdisciplinary collaboration is not an easy task in collaborative research, causing that in the majority of cases what we see is multidisciplinary collaboration (Holland 2008). Given this panorama, for the purpose of this study, the term cross-disciplinary collaboration will be used, as the more clear general term to name the focus of our coauthorship analysis in LIS papers, following the same term chosen by Bordons et al. (2004) or Porter and Chubin (1985).

All these terminological issues considered, we have noticed in the literature review that the term "interdisciplinary" is used in the LIS literature mainly as a general concept that encompasses three different situations:

1. Reception by LIS researchers of methodological and epistemological influences from other disciplines.

2. Coexistence of researchers from different scientific disciplinary affiliations under the same set of LIS publications, without coauthorship with researchers outside the field.

3. Cross-disciplinary collaboration in the form of coauthorship involving authors from different disciplinary departmental affiliations. Depending on the type of relationship and the level of integration of the teams, it could be considered "multidisciplinary", "transdisciplinary" or "interdisciplinary" collaboration.

As detailed in the literature review section, there is sufficient literature to provide evidence, from the perspective of the first and second definition, of the interdisciplinary nature of LIS. However, fewer works provide clear outcomes in accordance with the third definition. The outcomes of these studies show that the current level of "cross-disciplinary collaboration" does not support a generic and global statement about the interdisciplinary nature of LIS. Thus, we believe that more evidence is required to assess the degree of diversity among the disciplines of authors who publish in LIS serials, or to ascertain whether crossdisciplinary collaboration is strong enough to prove that multidisciplinary, interdisciplinary or transdisciplinary teams are firmly established.

The aim of this study is therefore to perform an analysis to obtain the disciplinary profile of players in those publications and the actual level of cross-disciplinary collaboration by identifying all the fields involved and their bilateral relationships. Because of the complexity of accurately identifying affiliations in terms of knowledge areas, we limited this study to authors from France, Germany, Spain and the UK, the four European countries with the largest number of papers in LIS publications indexed in Scopus, to present a valid representation of four different academic traditions and languages in LIS.

We understand that it is not appropriate to talk about the interdisciplinarity of LIS in a general sense, without providing greater clarity. It should be noted that this issue presents challenges to the scientometric classification of publications, the research assessment of the outputs generated by departments or individual researchers, and, last but not least, the academic policies involved in the transformation that LIS is undergoing because of the repositioning of undergraduate and graduate programmes and in the organizational restructuring of departments and schools. 
Certainly, the transformation that LIS is undergoing is reflected in a series of facts; many centres have opted for the iSchool movement, some have changed their name and some have been merged into larger organizational units with schools and departments in subjects such as communication, IT and education. In the search for accommodation in the new information society, a context that requires a broad approach to research, the traditional form of LIS is dissipating and there is ongoing debate concerning its teaching and research identity, which involves a wider variety of actors and is more complex than the traditional and historical duality between library science and information science.

In view of this situation, one may wonder if this increased organizational convergence with other cultures in academia, which can also be observed in professional workplaces such as libraries and information services, has fostered interdisciplinary research in the sense that there is greater collaboration between authors in diverse academic disciplines, and how LIS-affiliated authors perform in the bibliometric field of impact metrics compared to those with whom they may collaborate or coexist. Specifically, the work intends to answer the following research questions:

$R Q 1$ What is the share of the different disciplinary areas involved in the research published in Scopus-indexed LIS serial titles?

$R Q 2$ What is the level of cross-disciplinary collaboration among LIS-affiliated authors compared to authors in other disciplines who publish papers in Scopus-indexed LIS serial titles?

$R Q 3$ Which disciplinary areas perform best in terms of the distribution of papers by quartile in impact rankings like the SCImago Journal Rank (SJR) and the WoS Journal Citation Reports (JCR)?

\section{Literature review}

A significant number of papers have analysed the disciplinary variety of bibliographic references in papers classified in the field of LIS as an expression of the degree of reception of concepts, methods and data from other disciplinary areas, while others also analyse the distribution of citations received for such papers from other fields. The analysis of citations and co-citations, in both cited and citing publications, constitutes one of the main approaches to the phenomenon of interdisciplinarity, with respect to the first meaning of the term agreed upon in the introduction section. In this approach, the distribution of the authors' disciplinary affiliation is not evaluated.

For instance, Buttlar (1999) analysed 61 LIS studies conducted between 1994 and 1997 and found that approximately half of the citations that appeared in the studies referred to other fields, mainly education, computer science, health sciences, psychology, communication and business. Similarly, Tang (2004) analysed the citations in 150 publications in the field published between 1975 and 2000. The results show a wide variety of extra-disciplinary fields with a great deal of changes over more than 2 decades. According to her article, the influence of computer science on the field has grown since 1990, when LIS started shifting towards a more specialized technological position. Aström (2010) studied the relationship between information science and library science as LIS subfields, and found that the different citation patterns in the two areas were indicators of the interdisciplinary nature of LIS. Another example of this methodology is the work of Chen et al. (2018), who concluded from an analysis of references that Chinese LIS authors get almost 30\% of their information from sources outside of LIS publications. In a similar vein, Levitt and 
Thelwall (2009) analysed the origins of the top $0.01 \%$ citations in the most cited LIS articles in WoS, and observed the importance of links to other disciplines as a factor to explain the greater impact of those works.

The frequency of LIS citations in studies in other fields has also been measured. In general, the findings indicate a rise in the level of interest in LIS, especially from the fields of communication and media, computer science and technology, business and management, health sciences and engineering (Huang and Chang 2011; Meyer and Spencer 1996; Odell and Gabbard 2008; So 1988).

However, in relation to the second and third meanings for the term "interdisciplinary" agreed upon in the introduction section of this paper, i.e. the definition that involves assessing the diversity of disciplinary affiliations and the definition that traces cross-disciplinary collaborations, few works are available. Nevertheless, some papers can be used to contrast our data. Chua and Yang (2008) analysed the collaboration trends, authorship and keywords of all research articles published in the Journal of the American Society for Information Science and Technology from 1988 to 2007, and found a shift in the keywords from core information science towards other areas such as information technology and sociobehavioural science, that matches a trend to more intense cross-disciplinary collaboration, despite at the end of the period (2007) only reached the $36 \%$ of the papers. Aharony (2012) conducted a general descriptive profile of authorship patterns for 10 LIS journals alongside a content analysis of keywords and abstracts, which allowed her to analyse the distribution of the disciplines of the authors involved alongside the topics addressed and methods used in those papers, with an interesting outcome that shows the opening of LIS journals to authors from other disciplinary fields: LIS was the core discipline for only $36.36 \%$ of the authors. Huang and Chang (2011) found a growing openness to other disciplines according to the analysis of the bibliography cited in LIS journals and to the number of authors of non-LIS disciplines involved, although the tendency to publish in coauthorship showed a much smaller growth line. Chang and Huang (2012) combined a coauthorship analysis with citation and bibliographic-coupling analysis and observed that LIS researchers most frequently cited references to LIS journal articles and published in coauthorship articles with researchers affiliated with LIS-related institutes less frequently.

More recently, Chang (2018a) analysed contributors to 39 LIS journals and found that authors who were not affiliated with LIS-related institutions contributed to $46.5 \%$ of the papers, that the share of authors affiliated with LIS-related institutions decreased over the course of the years and that the share of works in cross-disciplinary collaborations between LIS and non-LIS affiliated authors was relatively low but constant. Chang (2018b) studied authors affiliated with LIS institutions who published in non-LIS journals, and found that most were academic librarians who published papers in medical and music journals, and that the level of cross-disciplinary collaboration was low. Chang (2019) measured the proportion of articles by authors affiliated with LIS-related institutions and concluded that, in only 25 out of 75 journals designated to the LIS subject category of JCR, the works contributed by LIS authors exceeded $50 \%$ of the total number of papers; moreover, journals with more non-LIS authors had greater impact factors. This trend is consistent with the answers of LIS journal editors surveyed by Ollé et al. (2016) who stated that the scope of their journals would expand towards related areas, such as Communication (32\%), Management (25\%), and Computer Science (19\%) in the coming years.

Other works have performed a kind of affiliation analysis, but have focused on dissertations. Prebor (2010) pursued an approach that involved the analysis of departments in which master's and doctoral theses were read and found that only a third of the research that was tagged on the ProQuest Dissertations and Theses database under either "library 
science" or "information science" (or both) was in fact conducted within an LIS department. Sugimoto et al. (2011) used academic genealogy network data from $\mathrm{PhD}$ dissertations in LIS over an 80-year period (1930-2009) to describe interdisciplinary changes in the field, and the results demonstrated a strong history of mentors from fields such as education and psychology, a decreasing trend of mentors with LIS degrees and an increasing trend in mentors receiving degrees in computer science, business and communication.

Whatever the approach taken to analyse the degree of interdisciplinarity through affiliation analysis, tracing the relationships established between LIS authors and fields other than LIS depends largely on the profile of the set of papers used for the analysis (Åström 2010; Odell and Gabbard 2008). Since WoS and Scopus are used as the main source for bibliometric studies and research assessment in terms of specific knowledge areas, the consistency and coverage of their journal classification systems also need to be addressed in our work as a collateral issue, due not only to the way they affect the mapping of relationships between disciplines, but also to the fact that, when assessing research, subject category rankings based on WoS or Scopus are used as a main disciplinary framework.

Obviously, the accuracy of a journal classification system can heavily influence the results of any study that analyses the level of interdisciplinarity/multidisciplinarity, productivity and research impact in the different scientific disciplines involved in a set of journals classified within the same field. For that reason, the precision of the WoS and Scopus journal classification systems has been a constant matter of concern among researchers, who have analysed several options to validate and improve them (Janssens et al. 2009; LópezIllescas et al. 2009; Zhang et al. 2010; Thijs et al. 2015; Gómez-Núñez et al. 2016; Urbano et al. 2005). Despite these efforts, Leydesdorff and Bornmann (2015) explored the use of WoS categories for calculating field-normalized citation impact indicators in the areas of information science and science and technology studies and concluded that the use of this category might seriously harm the quality of the evaluation. Van Eck et al. (2013) reached a similar conclusion in the case of health sciences.

A study on the visualization of LIS concept spaces by Åström (2002) concluded that journal selection affects how research fields are perceived and defined. However, this inference could be reversed, such that the definition of a research discipline corresponds to the set of journals included in such a discipline. This metonymic perspective is assumed when scientific assessment utilizes a ranking of selected journals in a field as an indicator of research quality in that field. In general, this practice presumes that research published in journals with a high position in WoS JCR, SJR and the Scopus CiteScore rankings is excellent and should be rewarded. The DORA declaration (2013) and the Leiden Manifesto (Hicks et al. 2015) have warned against this procedure, but such journal-based evaluation systems are used in several countries, including Brazil, Colombia, South Africa, Spain and Taiwan (Chavarro et al. 2017b; Ràfols et al. 2016; Tseng and Tsay 2013; Vessuri et al. 2014). It is also important to consider that the inclusion of a journal in WoS seems to be based on entirely objective criteria, but the likelihood of inclusion depends on the country, language and discipline, regardless of its editorial quality or impact (Chavarro et al. 2017a).

Odell and Gabbard (2008) pointed out that, after 1994, JCR included fewer journals that addressed aspects of librarianship, which have been replaced by journals with a greater emphasis on information technology and information science research. Abrizah et al. (2015) studied the sub-categorization of the information and library science journals listed in the 2011 edition of JCR. Based on the opinions of 243 active authors and editors with publications in the field of LIS, the 83 journals were classified as library science, information science, information systems and "don't know" or "undecided". Based on the count, 
respondents assigned 39 titles to the first category, 23 titles to the second, 21 titles to information systems and 21 titles to the "unknown" category. However, only one title in library science was in the highest quartile due to its impact factor, compared to eight titles in information science and 11 in information systems. Chang (2019) found that, in the 2017 edition of JCR, the first library-oriented journal was positioned in 26th place in the impact factor ranking. This shows that traditional library science journals are poorly represented among the top $25 \%$ in terms of JCR's impact factor ranking.

Since institutional or national frameworks for the assessment of individual research implicitly encourage authors to publish in the first quartile, LIS academics face challenges when it comes to undertaking library science research, because journals in this field are ranked lower than those of information science, information systems and specialized fields of information resources and services, such as medical and geographical information. In other words, scholars may be tempted to refocus their interest on information science or information systems to survive in the academic world. This situation can present a quandary for practising librarians with faculty status seeking promotion and tenure, since they are advised to publish in the top journals in the category (Best and Kneip 2010). This aspect perhaps reinforces the academic-practitioner gap detected in LIS (Ardanuy and Urbano 2019) and the need to publish in fields outside LIS, and puts additional pressure on academic librarians to collaborate with scholars (Borrego et al. 2018).

\section{Materials and methods}

This study examined the degree of cross-disciplinary collaboration in the scientific output and the share of participation of authors from different disciplines in LIS serials through the analysis of affiliations and coauthorship. In the literature review, we have noticed the existence of various methods to analyse interdisciplinarity among a set of publications or in an area of knowledge, methods summarized by Bordons et al. (2004) in 4 approaches: (1) tracking the collaboration between authors with different academic training, background or affiliation; (2) performing a content analysis of the works, through the presence of keywords or classification codes from different disciplines in documents, or even exploiting the full text through text-mining; (3) analysing the dispersion in different disciplinary categories in bibliographical databases of the of the journals where the set of works analysed have been published; and (4) mapping the knowledge transfer between disciplines, through citation analysis of cited and citing works, or through the study of the migration of scholars to a new disciplinary unit in their organization.

Our methodological choice of the authorship affiliation and coauthorship analysis is based on precedents that have used such single approach (Abramo et al. 2012; Chang 2018a, 2019; Schummer 2004), as well as other works in which various methodologies were combined with authorship analysis (Aharony 2012; Chang and Huang 2012; Huang and Chang 2011; Jamali et al. 2018; Jokić 2020; Qin et al. 1997). Given the objectives of our work and the scope of our project, our methodological choice was considered sufficient, although acknowledging that it is just one of several possible approaches.

This approach assumes that "in each area and at any time, the level of differentiation corresponds to what the scientific community itself considers distinct disciplines and what not" (Schummer 2004). This procedure makes it possible to determine two things with great precision: first, the level of "coexistence" of authors from different disciplines who publish but do not collaborate in the same set of publications in a given subject category 
from a recognized bibliometric source; and second, the level of cross-disciplinary collaboration that is a condition for qualifying any scientific output as multidisciplinary, interdisciplinary (in the specific, more restrictive definition of the term) or transdisciplinary research.

An analysis of authorship affiliation was performed to identify the disciplinary links and cross-disciplinary collaboration of authors from France, Germany, Spain and the UK involved in research output published in LIS serial titles indexed in Scopus during the 2010-2017 period. The scientific output was selected from serial titles included in the "Library and Information Sciences" subject category of the 2013 SCImago Journal \& Country Rank (SJR). We obtained bibliographic records for the papers in 209 serials included in that subject category from Scopus; these were mainly journals. Any changes made to titles during the period, such as the Journal of the Association for Information Science and Technology (JASIST), were considered. Scopus was used as a source because this database provides access to a greater number of publications in the LIS field than the equivalent category in Web of Science (WoS) for the chosen time frame. Consequently, using Scopus made it possible to consider a greater number of titles and thus achieve better coverage for titles in languages other than English.

However, in the LIS SJR subject category, $72 \%$ of the titles belonged to two or more categories, and almost $20 \%$ to four or more categories. This means that many titles overlapped with both the humanities and social sciences, as well as with the experimental sciences and technology. We therefore decided to reduce the noise caused by publications that are included in SJR's LIS category that deviate too much from the mainstream to obtain a more consistent list of titles linked to LIS research, but with a certain level of openness to research disciplines related to the information world. To achieve this, we compared the profile of the literature cited by each serial title against the average profile of works cited by the whole set of 209 titles.

To obtain that average citation profile, a $5 \%$ truncated mean was calculated for the number of citations granted from the 209 citing titles to each of the 1500 or so cited serial publications that could be clearly identified. The correlation coefficient between the number of citations granted by each citing journal and the number of citations of the average profile was then calculated. According to this calculation, Aslib Proceedings: New Information Perspectives had the highest Pearson correlation coefficient (0.8), whilst publications such as Lecture Notes in Control and Information Sciences and Information Systems Research had a negative coefficient. This assumed that the lower the coefficient values, the greater the disciplinary distance with respect to mainstream information use by the authors who publish in the LIS field. The list of 209 titles was divided into quartiles by decreasing values of the Pearson coefficient obtained. Titles in the last quartile were excluded, except for some archival science journals to guarantee representation of that core branch within LIS, given the endogenous dynamics of citation in the ecosystem of archival science publications. This left a total of 170 titles to examine (see supplementary data annex), from which 8537 records, corresponding to papers published between 2010 and 2017 by British, French, German and Spanish authors, were retrieved from Scopus by March 2018. Exploitation of the data resulted in a total of 13,189 authorships, not single authors, since we intended to observe the number of occurrences of actual collaborations, not the number of authors.

Next, a rigorous and laborious process of identifying the authors' affiliations was carried out by checking the authorship of each paper. Attribution of affiliations to authors was a complex process that required the use of the affiliation statement from the Scopus database as a starting point, but that was complemented with information from the paper itself 
and additional research from other sources, because the publication source does not always provide enough information about affiliations.

To illustrate the challenge involved in performing affiliation analysis these days (simply put, without the robust implementation of identifiers such as ORCID), we calculated, in the case of universities and higher education institutions, the level of detail of the affiliation statements directly provided in the publication sources we consulted: in $28.7 \%$ of the total authorships, the only affiliation mentioned was the name of the university and there was no other reference to the functional activity or knowledge area of an organizational unit under the general umbrella of the university. Such information can include, for example, a member of the library team, technical staff involved in digitization processes and members of LIS academic staff, without any information to differentiate them. A total of $33.5 \%$ of authorships showed as belonging to a specific academic department, which made it possible to identify the knowledge area to some degree; $22.6 \%$ specified a school, faculty (in the European sense) or other academic unit, such as the French concept unité de formation et de recherche; $10.9 \%$ mentioned university research centres; $3.6 \%$ indicated university research groups; and $0.7 \%$ mentioned other situations. No significant temporal variations were detected in the period analysed. However, there were important variations between the countries analysed, as shown in Table 1; in the case of Germany, major differences were observed when proceedings were considered in addition to journals. In terms of source, affiliation was usually limited to the name of the university. The figures for Spain were notable in that most affiliations included the specific department.

The data illustrate that it was not an easy task to establish the disciplinary area of the authors based only on the names of the organizational units they belonged to and the hierarchical position of those units within the organization. It was necessary to look for more specific information about the authors in organizational information obtained from the websites of the universities, companies and other institutions. Also, it was necessary to complement the information with scientific social networks, direct consultation and other research efforts to shed light on ambiguous situations such as hybrid departments involving more than one knowledge area and authors working in professional settings such as libraries, archives and other information services. Whenever it was not possible to establish a disciplinary link, we classified authors for whom we did not have enough information in two possible special categories: "Professional staff without any clear disciplinary link" for people who at least had a clear professional status, and "Not established" for people for whom no disciplinary or professional profile could be established.

However, when capturing affiliation data, two limitations must be taken into account. First, we considered only the first affiliation of each author, in cases where two or more independent organizations were linked to the same author, for example in the case of two universities. Second, we worked with the disciplinary links of authors, assigned as a result of the professional, research or academic unit to which they belonged and the subject profile of their bibliographical output, but not through their graduate or postgraduate academic background, since teachers in LIS departments usually have very diverse academic qualifications.

Moreover, it should be stressed that the exploitation of the data we collected provided evidence of cross-disciplinary collaboration, but no further granularity in terms of the type of collaboration. Thus, we cannot conclude whether the works are simply an expression of the multidisciplinary juxtaposition of author approaches or whether they present the level of integration required to qualify a research paper as interdisciplinary or transdisciplinary (Holbrook 2013; Schummer 2004). At this point, it is worth quoting Klein (1990, p. 56): “Most purportedly 'interdisciplinary' activities are not 'interdisciplinary' but 


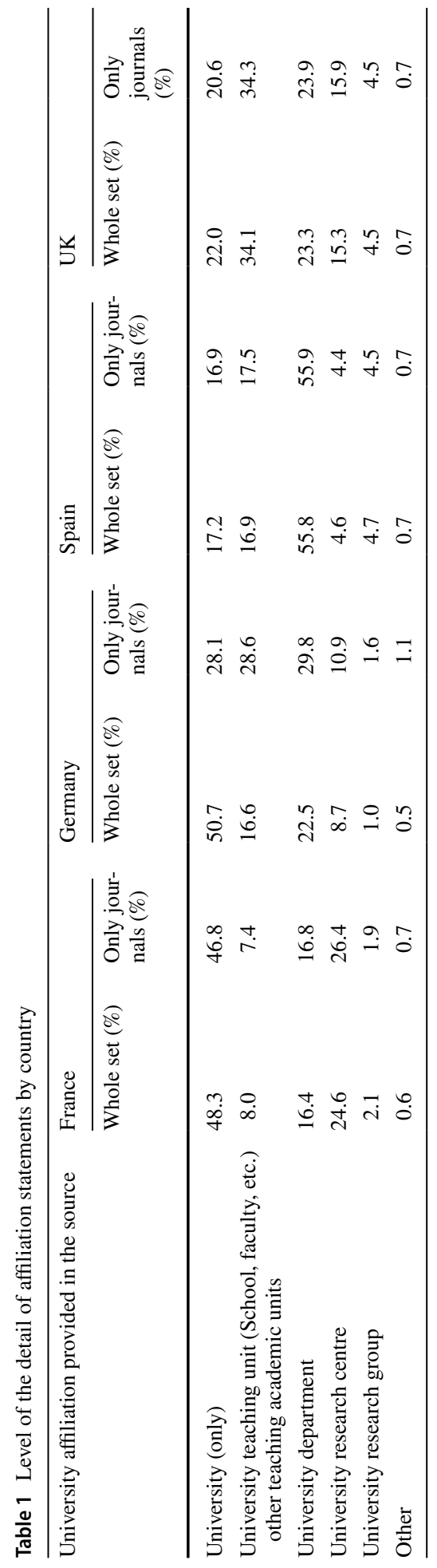


'multidisciplinary' or 'pluridisciplinary'. 'Multidisciplinarity' signifies the juxtaposition of disciplines. It is essentially additive, not integrative." For this reason, a decision was taken to inquire about the level of cross-disciplinary collaboration in this research, since this is a necessary condition for both juxtaposition and integration. Further studies consisting of thorough content analysis of the actual papers and direct methods of data collecting involving interaction with the authors themselves (through surveys, interviews, etc.) would have been necessary to qualify the extent of collaboration with a higher level of granularity.

\section{Results and discussion}

The total number of bibliographic records analysed in the study was 8537 , which corresponded to 13,189 authorships (any single contribution from any of the authors involved in any paper). Of these, $85.0 \%$ were contributions to journals, $14.0 \%$ were conference proceedings and $1.0 \%$ were book series. Out of the whole set, the percentage of authorships from the field of LIS was $30.3 \%$, which means that nearly $70 \%$ of the authorships corresponded to authors from other knowledge areas (Table 2). A total of $18.1 \%$ of the whole set were from the field of Mathematics and computer science, followed by $12.2 \%$ from Business, general management and economics, and 10.2\% from Management information systems (hereinafter "MIS"). When journal papers alone were taken into account, the percentage of LIS authorship increased to $34.1 \%$ because of the prevalence of conference proceedings in areas such as Computer Science and MIS. The substantial contribution of the three non-LIS fields mentioned above, which are joined by many other fields with a lesser presence, offers a clear insight into the considerable dispersion of knowledge areas involved in publications classified within the Scopus subject category of LIS. This finding is consistent with previous works that have studied the presence of non-LIS affiliated authors in the LIS scientific communication ecosystem (Aharony 2012; Ardanuy and Urbano 2015b; Chang 2018a).

Table 2 Share of authorships in LIS publications by knowledge area

\begin{tabular}{lll}
\hline Knowledge area & $\begin{array}{l}\text { Percentage (whole set) } \\
(\%)\end{array}$ & $\begin{array}{l}\text { Percentage } \\
\text { (only journals) } \\
(\%)\end{array}$ \\
\hline Library, archival and information science (LIS) & 30.3 & 34.1 \\
Mathematics and computer science & 18.1 & 18.4 \\
Business, general management and economics & 12.2 & 11.7 \\
Management information systems (MIS) & 10.2 & 3.5 \\
Experimental sciences and engineering & 6.5 & 6.7 \\
Media and communication & 6.5 & 7.5 \\
Legal and other social sciences & 6.3 & 7.0 \\
Health sciences & 3.5 & 3.9 \\
Education & 2.0 & 2.2 \\
Humanities and arts in general & 1.8 & 2.0 \\
Behavioural sciences & 1.3 & 1.4 \\
Not established & 0.8 & 0.9 \\
Professional staff without any clear disciplinary link & 0.6 & 0.7 \\
\hline
\end{tabular}


To gain a better overview of the research output channelled through publications classified as LIS serials, it is essential to take account of the level of collaboration, whether cross-disciplinary or not, because this represents a key indicator of the evolution and complexity of the research projects from any field or scientific communication ecosystem. However, beyond this, the key objective of this work was to determine whether co-authored papers involve collaboration from more than one knowledge area, and what areas present the strongest relationships. Thus, we calculated the share of articles with collaborations out of the total output analysed (Table 3), a figure that reached a $46.9 \%$ of co-authored papers; a consistent data with the $45.2 \%$ found by Ardanuy and Urbano (2015a) in their study that analysed the 2010-2014 period and considered all EU countries based on similar sources. It is also close to the $51.17 \%$ obtained by Huang and Chang (2011) for the period 1978-2007 and papers from only five top impact journals; that data contrast with the share of $79.3 \%$ of co-authored papers obtained by Chang (2018a) in a sample of papers obtained from a selected set of 38 journals published only in English for works contributed by nonLIS authors.

Of the total number of articles with collaborations, $36.6 \%$ were between authors from different fields, thus indicating that only $17.1 \%$ of the papers involved cross-disciplinary collaboration, and $7.7 \%$ of cross-disciplinary collaborations involved LIS-affiliated authors (Table 3), a figure slightly below the trend observed by Chang (2018b) in her study, which ranged from around $10 \%$ to $15 \%$ between 2005 and 2014 .

Attention should be paid to metrics of general collaboration in coauthorship, in order to understand the cross-disciplinary collaboration figures obtained in this study: the values obtained are modest, but aligned with what happens in a good number of fields in the social sciences in general and in LIS in particular. The degree of general collaboration, measured as the average number of authors per article (Collaborative Index), is 1.3, with a range from 1.1 to 1.5 according to the area of knowledge considered; and the Degree of Collaboration (DC, expressed as a percentage, not as a ratio) is $46.9 \%$, with a range from 39.4 to $62.5 \%$ (Table 4). Those figures are aligned, for instance, with a CI of 1.8 and a $47 \%$ of papers in collaboration (DC in \%) in the case of LIS Spanish authors indexed in WoS and Spanish LIS journals for the year 2015 according to the database Co-Author Index of the Universidad de Granada EC3 research group (http://www.coauthorindex.info/). That is, the potential for cross-disciplinary collaboration in the set of papers we have analysed is limited by a relatively low level of the general indicators of collaboration, both in the number of authors per paper and in the percentage of papers published in co-authorship; figures that for affiliated authors in LIS $(C I=1.3$ and $C D=39.4 \%)$ are below other knowledge areas.

When the overall data on the share of papers with cross-disciplinary collaboration were disaggregated by area (Table 4), it was clear that the only authors who publish more than $50 \%$ of their work with cross-disciplinary collaboration were those in the area of health sciences, together with professionals who could not be assigned to any discipline. It should be noted that the areas with the greatest collaboration were those that produce the smallest

Table 3 Detail of the level of collaboration in the whole set of 8537 papers

\begin{tabular}{lrr}
\hline Papers without collaboration (only one author) & 4537 & $53.1 \%$ \\
Papers with any type of collaboration (co-authored papers) & 4000 & $46.9 \%$ \\
Papers with cross-disciplinary collaboration & 1464 & $17.1 \%$ \\
Paper with cross-disciplinary collaboration involving LIS-affiliated authors & 656 & $7.7 \%$ \\
\hline
\end{tabular}




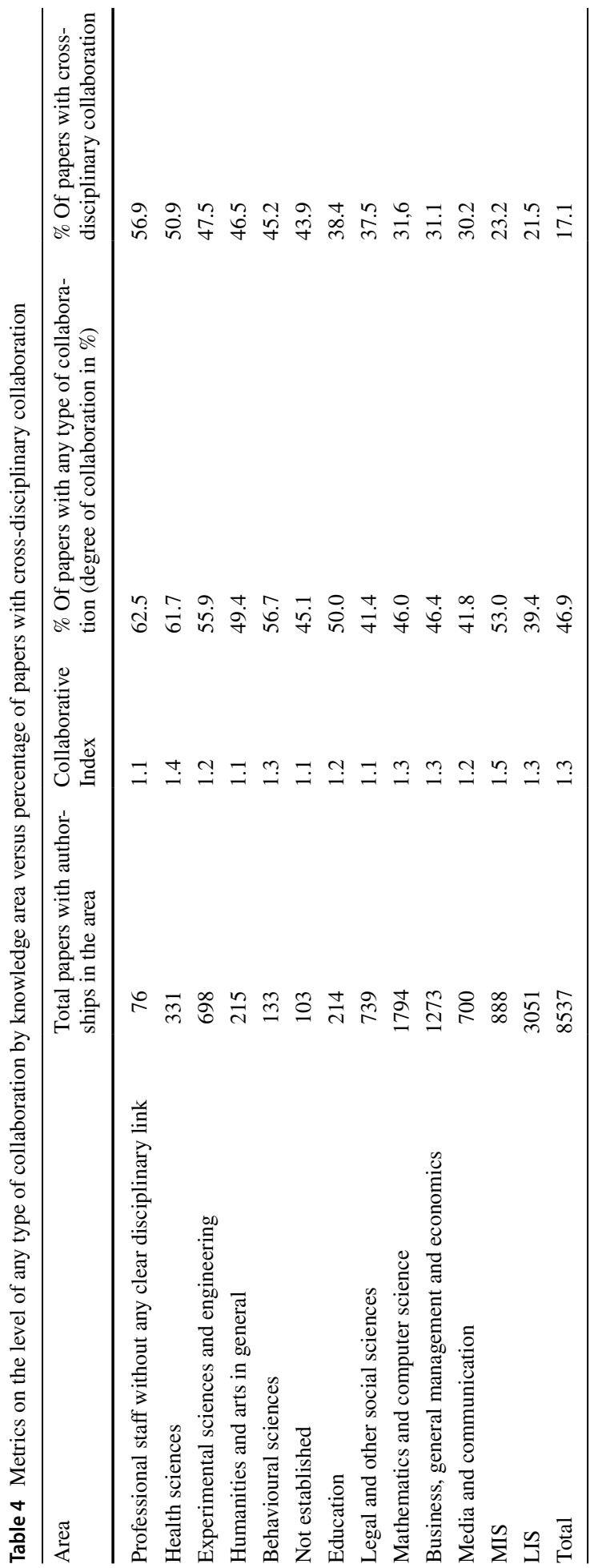


number of papers, while those that played a central role in terms of volume and occupied a central position due to their association with information studies and computer science (LIS; MIS; Business, general management and economics; and Mathematics and computer science) presented a lower percentage of cross-disciplinary collaboration. The fields of MIS and LIS fell into this category, with $23.2 \%$ and $21.5 \%$, respectively. It is worth noting that authors from the field of LIS contributed to 3051 papers (35.74\% of the total papers), while just $21.5 \%$ of papers by LIS authors were carried out with cross-disciplinary collaboration.

If the topic of collaboration between fields is examined with a higher level of granularity and the bilateral relationships between the areas are explored (Table 5), the percentage of collaborations by each field with all others can be observed. For each field in the rows, the percentage is calculated with respect to the total number of collaborations of the field in the row. As a result, the matrix is not symmetrical. For instance, $40.9 \%$ of the collaborations by MIS were carried out with Business, general management and economics, but of the total number of collaborations by this field, $21.1 \%$ were with MIS.

By reading this table horizontally, it is possible to detect the areas with the highest percentage of collaboration with other areas. Thus, the areas in the columns with higher percentages than the areas represented in the rows play a central role in the scientific communication ecosystem analysed. Three fields lead the way in terms of cross-collaboration; in first place is LIS, with which eight areas carried out their maximum percentage of collaboration, followed by Mathematics and computer science, with four areas, and Business, general management and economics, with one area.

If the case of LIS is analysed in more detail, it becomes clear that all fields, with the exception of the Professionals without any clear disciplinary link (49.5\%) and Media and communication $(42.1 \%)$, present modest percentages in terms of cross-disciplinary collaboration with LIS and a very weak relationship with other areas that are strong in terms of the number of papers and impact of the journals in which the papers are published; for instance, the low share of collaborations with LIS among MIS authorships (8.6\%) contrasts with the strong relationship of MIS with Business, general management and economics (40.9\%) and with Mathematics and computer science (31.2\%). The low volume of output and authorship in collaboration with LIS authors by researchers in areas such as psychology, education and the humanities is also noteworthy, given that a significant volume of LIS work has traditionally focused on these areas.

For all these reasons, and in view of Tables 3, 4 and 5, it can be concluded that the degree of collaboration by authors affiliated with the field of LIS with non-LIS authors is not strong enough to regard LIS as the interdisciplinary field that it is often claimed to be. We can at least argue that it is mildly interdisciplinary from the point of view of partnerships. This low level of collaboration between LIS and non-LIS areas should be put in the context of the huge presence of non-LIS authors in the set of serial titles analysed. The data suggest that the presence of non-LIS authors in this set of publications from the SJR LIS category can be explained by the fact that many titles are assigned to more than one SRJ subject category; this implies that high-impact titles from very specific fields of research that represent a natural habitat for non-LIS authors (such as specialized MIS publications) have a major presence in the SRJ LIS category. Moreover, a large number of publications devoted to scientific communication and research evaluation are classified in this category, but these journals could actually be considered a kind of interdisciplinary space for authors with highly diverse backgrounds, because bibliometricians from LIS institutions are not the only people to publish bibliometric and scientometric papers these days. Finally, another important explanatory factor is the 


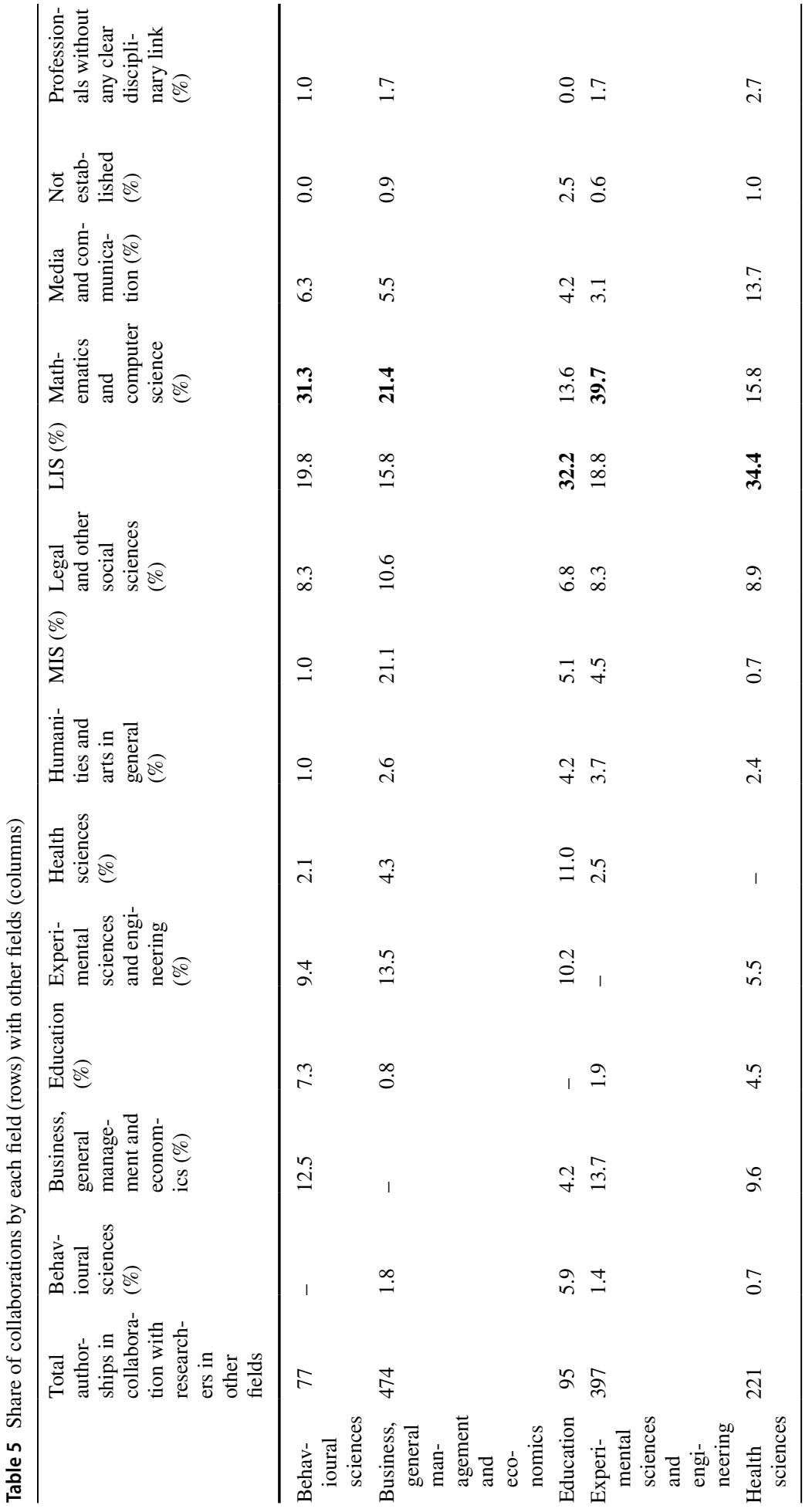




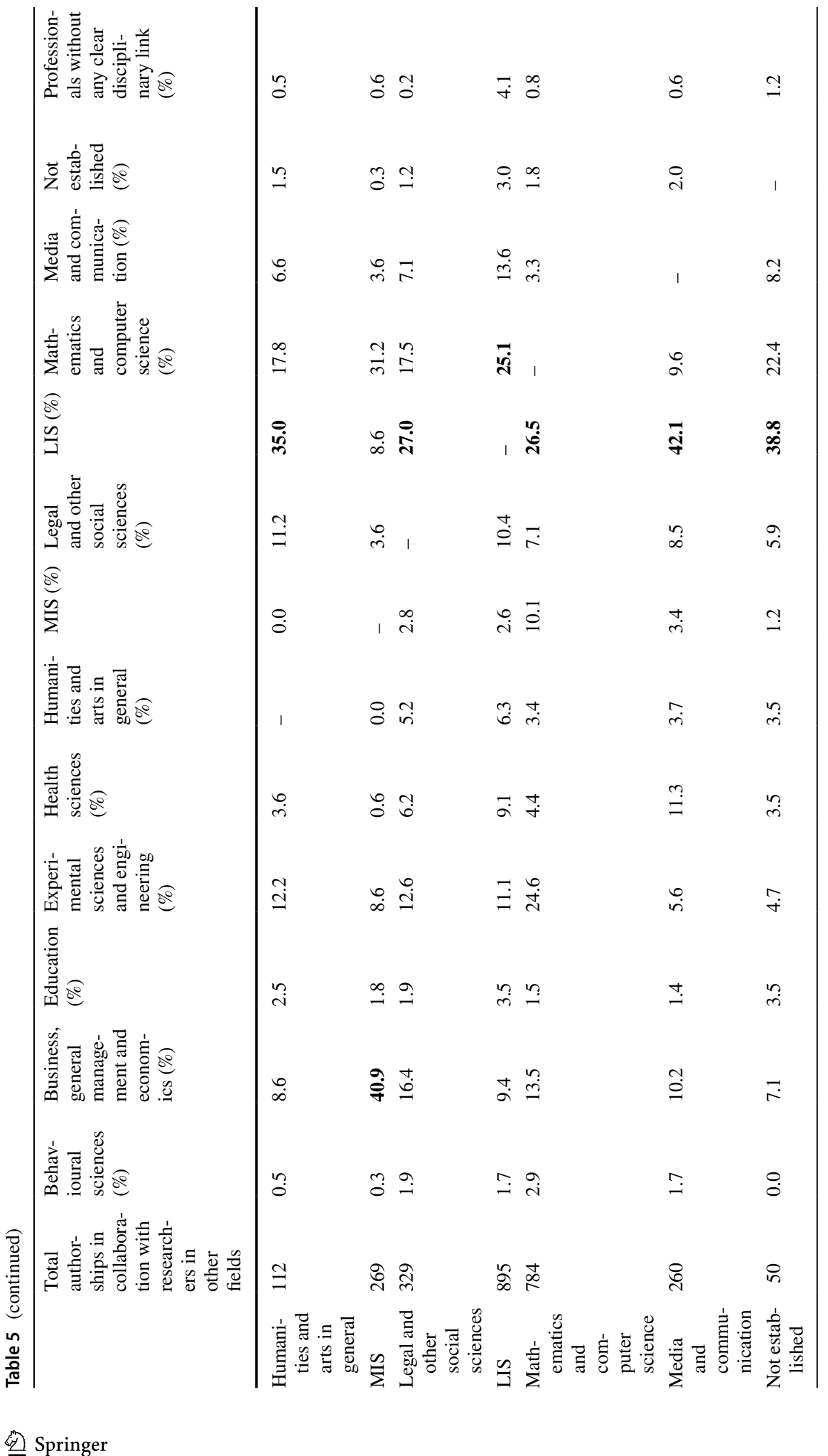




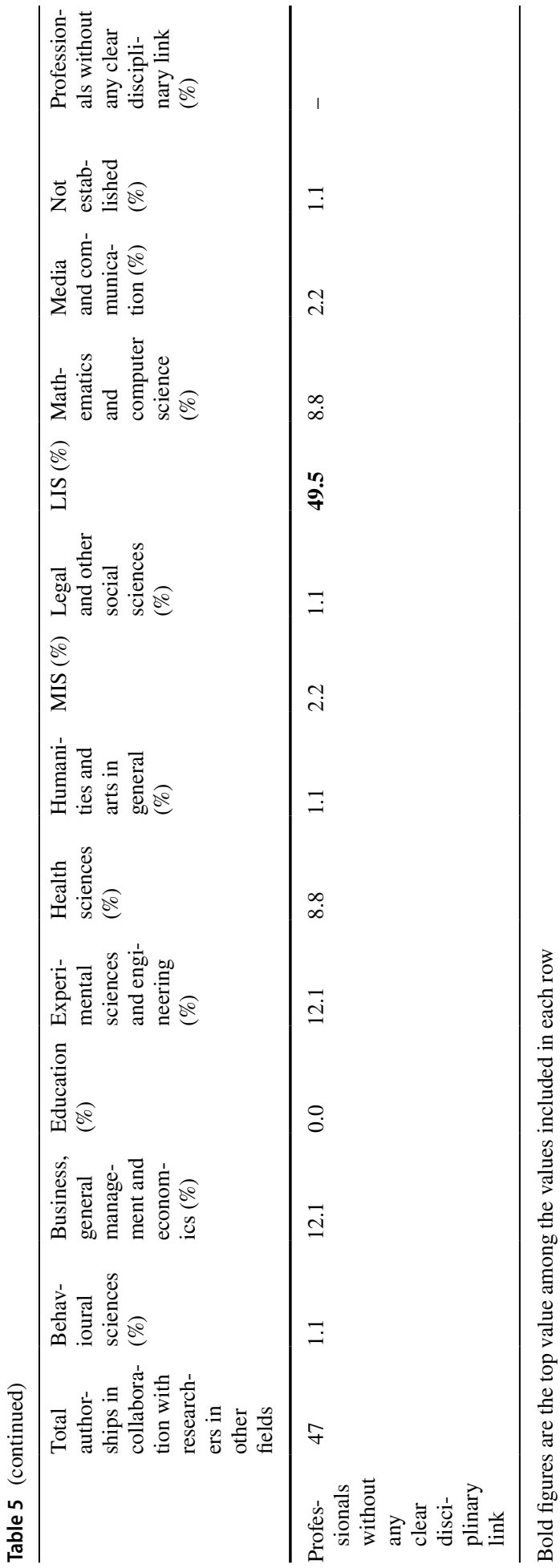


breadth of topics addressed and approaches taken by many LIS publications that have been targeting new clients in recent years to increase their economic and "bibliometric" sustainability and broaden the scope of their calls for papers.

Furthermore, to contextualize the results of the analysis of the authors' disciplinary affiliations and collaborations, we searched for output patterns by country and discipline, top publications by country, language by field, the academic status versus professional profiles of authors, and the impact rankings of the journals in which the different knowledge areas publish. As might be expected, there were several important differences in the distribution of authorships by area between the four countries (Table 6). These results are qualitatively consistent with those reported in the study of keywords used by EU authors in LIS publications (Ardanuy and Urbano 2015a). For LIS, the percentage ranges from $38.3 \%$ in Spain to $19.7 \%$ in France. However, when journal papers alone are taken into account, Germany reaches $41.4 \%$ in LIS, a figure that exceeds Spain's $38.3 \%$. This is because most of the proceedings included in the Scopus LIS category are related to MIS and authors from Germany are the main contributors, as shown in Table 7; the German contribution to the Americas Conference on Information Systems was huge, at $25.4 \%$.

Some differences between countries in the share of authors' knowledge areas are linked to the ranking of publications with most authorships in each country shown in Table 7, which illustrates the journals or proceedings with the top eight share of authorships by country and reveals the different publishing cultures of each country. Some of these differences can be explained by the narrower international scope of journals such as El Profesional de la Información, Zeitschrift für Bibliothekswesen and Documentaliste: Sciences de l'Information, whose content is not primarily in English, and also by the importance attached to areas such as MIS and computer science in Germany and France, in comparison to the dominance of LIS in Spain and the UK. In this regard, the percentage of authorships in languages other than English varies greatly according to knowledge area (Fig. 1). In the case of LIS, $40.1 \%$ are in other languages. This figure contrasts with $98 \%$ in the case of information systems. These data are consistent with previous studies on the distribution and language uses of journals (Ardanuy and Urbano 2015a, b).

The professional profile of authors with a LIS affiliation was also analysed according to whether they were scholars or practitioners within information centres, or performed other functions (Fig. 2). The general overview shows that $52.6 \%$ were lecturers or researchers in university departments, research centres or higher education institutions (such as business schools and grandes écoles). A total of $34.7 \%$ were attached to libraries and $7 \%$ worked in other professional settings (3.2\% worked in information centres such as documentation centres and archives; $6.6 \%$ performed non-librarian or documentation specialist duties in companies and non-profit organizations; $1.9 \%$ were independent consultants; and $1.0 \%$ belonged to professional associations). However, significant differences were observed in the percentages of academics and professionals according to country. Thus, while $71 \%$ of the authorships in Spain were academic, the percentage in the United Kingdom was 53\% and as low as $34 \%$ and $25 \%$ in Germany and France, respectively.

This strong presence of authors from the professional field, regardless of whether they were classified by discipline, helps contextualize the low level of cross-disciplinary collaboration as a whole, since much of the work by these professionals consists of the communication of experiences and case studies that are not explicitly linked to research projects, and the authors of which are the professionals of the centres. As analysed in other works (Ardanuy and Urbano 2019), there is a considerable gap between scholars and professionals that helps partially explain the low level of cross-disciplinary collaboration, since $47 \%$ of the total authorships corresponded to non-academic staff. 


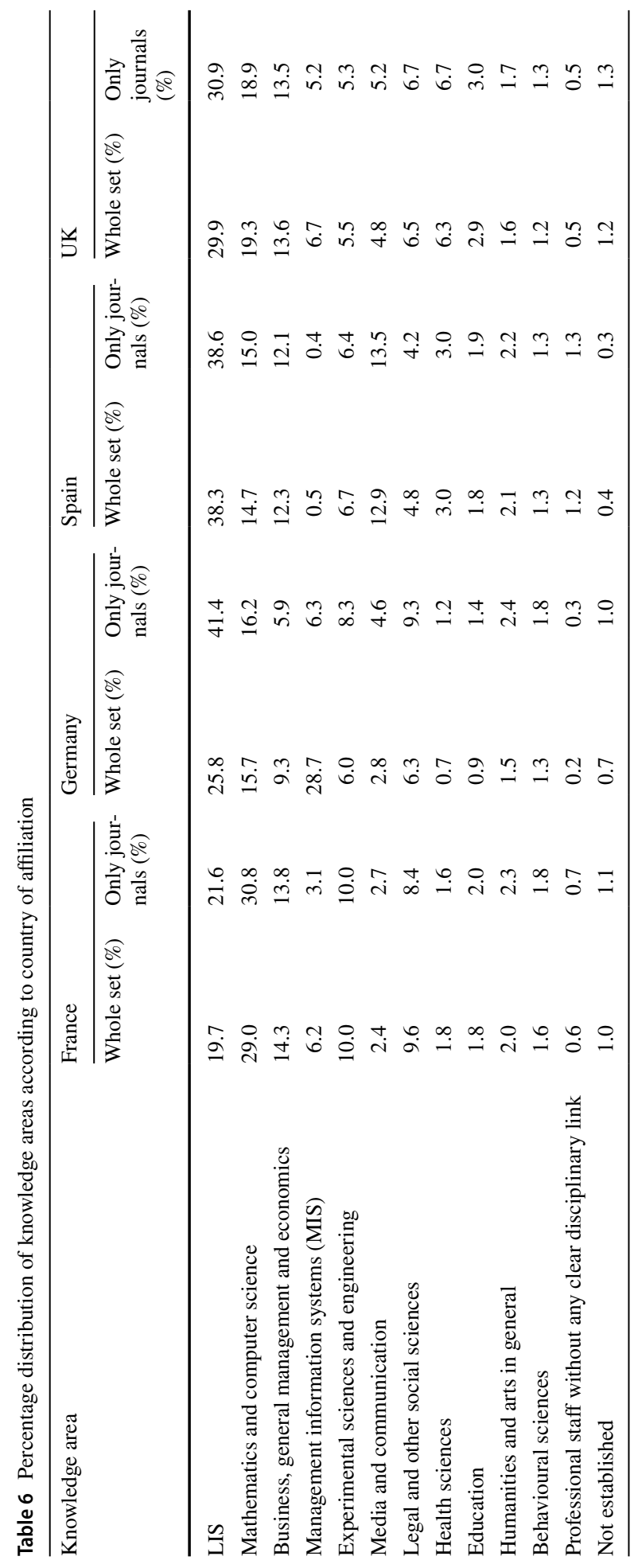




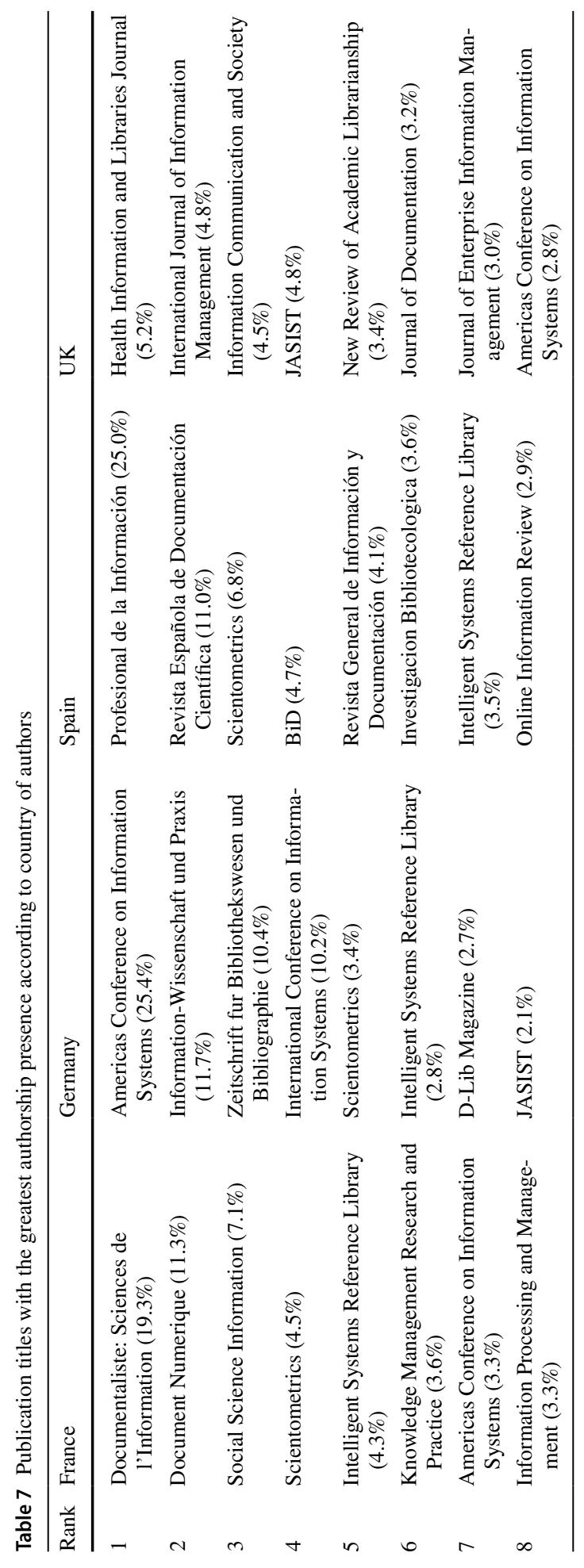




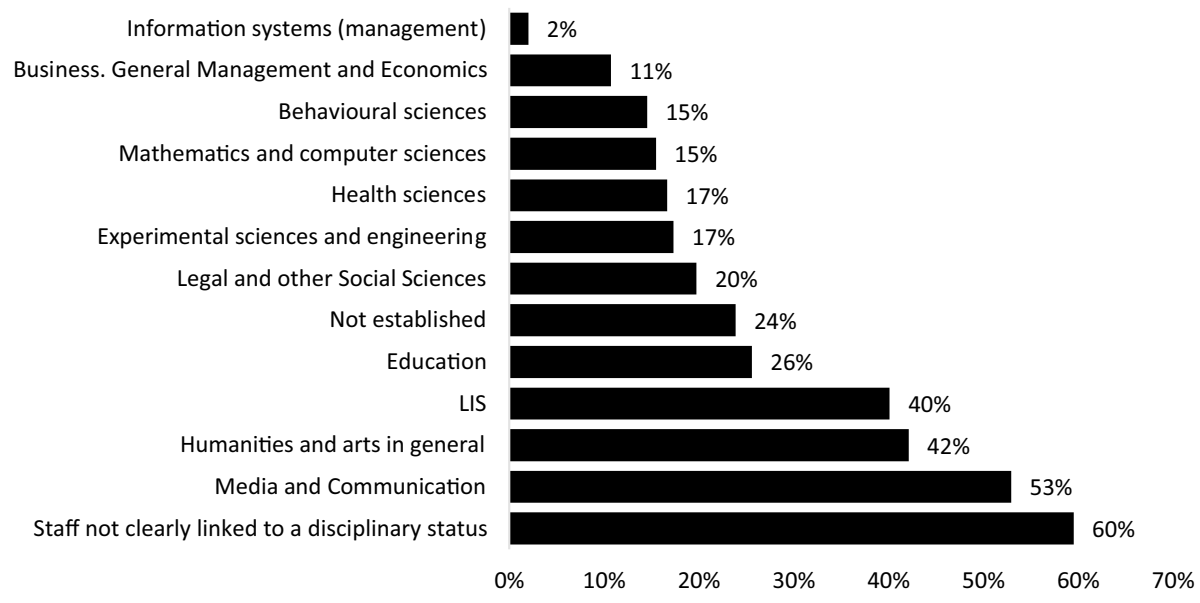

Fig. 1 Percentage of authorships in non-English papers according to knowledge area

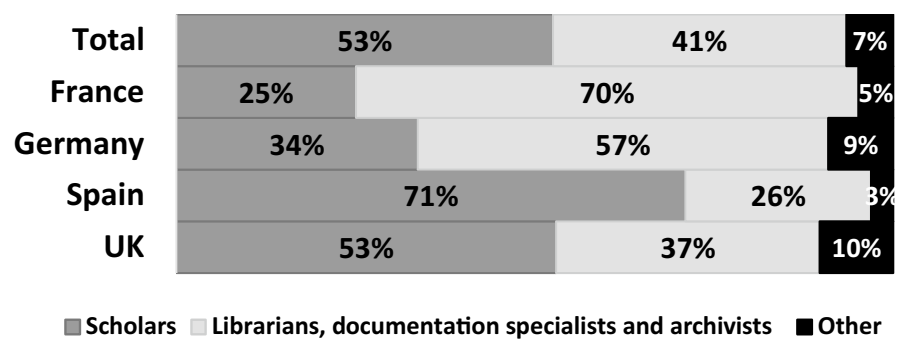

Fig. 2 Percentage of scholars and practitioners of authorships with a LIS affiliation

The number of authorships by area linked to titles ranked by quartile in the SJR and JCR editions corresponding to the publication year of each paper studied was also analysed. Table 8 shows the proportion of authorships linked to each quartile in relation to the total output of each knowledge area in the case of SJR. The data obtained reveal a clear picture: the highest presence in the first quartile, and in the first and second quartiles combined, corresponded to authors from areas outside LIS, because the majority of publications in the highest percentile rankings in the SJR LIS subject category focused on MIS, information technology or health information. An analysis of their presence in WoS JCR (Table 9) confirmed this fact; in both rankings, MIS (management information systems) had the highest output percentage in the first quartile and LIS the lowest.

These data confirm that, among first-quartile journals in SJR or JCR, there is a preponderance of journals that publish work by authors from scientific and technical disciplines with more demographic power and who focus on topics related to these disciplines (such as management, computer science and medicine), thus confirming that these four countries present the general trend observed by Huang et al. (2019) and Chang (2019). On the other hand, many of the works analysed by authors from France, Germany and Spain focus on national and non-specialized library science journals 
Table 8 Distribution of authorship by SJR quartiles by knowledge area, ranked in descending order in the first quartile

\begin{tabular}{lllll}
\hline Knowledge area & 1st Q $(\%)$ & 2nd Q (\%) & 3rd Q (\%) & 4th Q $(\%)$ \\
\hline MIS & 65.0 & 23.4 & 8.4 & 3.3 \\
Business, general management and economics & 51.1 & 31.0 & 8.6 & 9.3 \\
Mathematics, computing and IT & 45.8 & 25.4 & 13.9 & 14.9 \\
Experimental sciences and engineering & 45.1 & 23.8 & 18.3 & 12.7 \\
Media and communication & 41.1 & 26.1 & 22.1 & 10.7 \\
Other knowledge areas & 41.0 & 27.0 & 17.8 & 14.3 \\
LIS & 28.6 & 27.0 & 24.2 & 20.1 \\
\hline
\end{tabular}

(Table 7), most of which are not published in English, have a less international audience, and are therefore less likely to be cited.

\section{Conclusions}

An analysis of the data obtained allowed us to provide some answers to the research questions posed at the beginning of this study for the four countries studied: the share of the different disciplinary areas involved in the research output published in Scopus LIS serial titles (RQ1); the level of cross-disciplinary collaboration among authors with LIS affiliations compared to other disciplinary areas (RQ2); and the disciplinary areas that rank highest in terms of the distribution of their papers by quartile in impact rankings such as SJR and JCR (RQ3).

LIS departments or institutions barely account for a third of the research output published in serial titles under the LIS subject category

- The selection of titles classified by Scopus or SJR under the subject category LIS presented a wide distribution of authors who corresponded to different disciplinary areas. The authors affiliated with LIS institutions barely represented $30.3 \%$ of the total $(34.1 \%$ when journals alone were considered). Six other areas reached between $6.3 \%$ and $18.1 \%$ of the authorships out of the total number of serial titles, and authors who focused on the areas of computing, business management and information management played a leading role.

Cross-disciplinary collaboration among all areas is low, but is particularly low in LIS compared to other areas that contributed to the set of papers analysed

- Only $17.1 \%$ of the 8537 articles analysed were authored with cross-disciplinary collaboration, although it is unclear whether the type of collaboration was simply multidisciplinary or whether an integrative design research approach within interdisciplinary or transdisciplinary teams was taken. This low level of cross-disciplinary collaboration and the high number of different disciplinary areas that contributed to the LIS subject category of serials led us to use the term "coexistence" to describe the situation.

- This lack of cross-disciplinary collaboration is especially notable in the case of authors affiliated with LIS centres, since they participated in 3051 papers, just $21.5 \%$ of which 


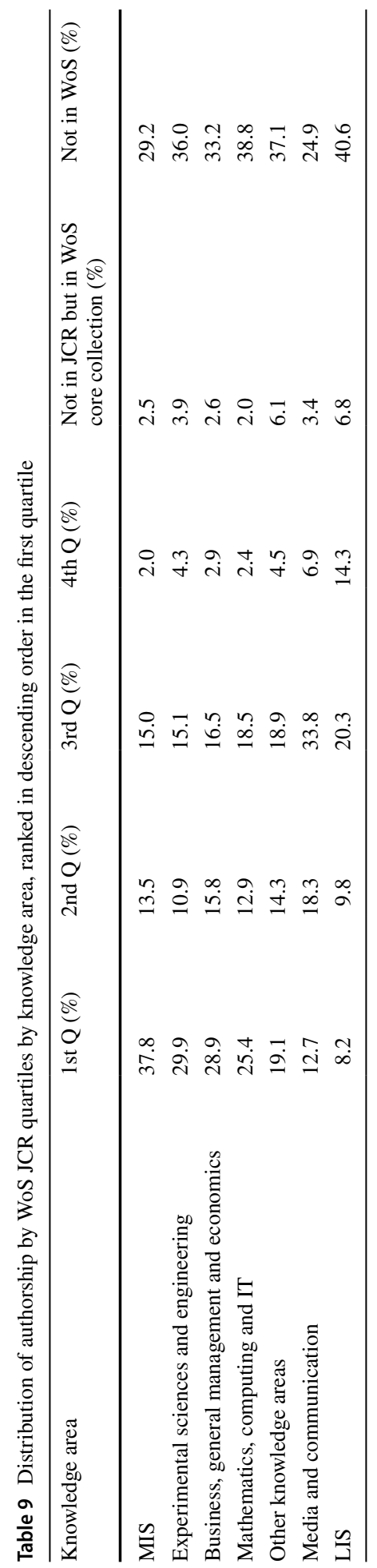


mentioned collaboration with authors from other areas, the lowest percentage observed with respect to the areas analysed. Thus, out of the total of 8.537 papers, only $7.7 \%$ of cases presented cross-disciplinary collaboration with the participation of LIS-affiliated authors.

The low level of cross-disciplinary collaboration in LIS contradicts, from the point of view of authorship, the interdisciplinary nature of LIS purported in the literature

- Although the present study did not include a content analysis of the papers to determine the research topics or methodologies involved, an abundant, consolidated body of literature supports the theory that LIS is a meta-discipline (as defined by Bates) because of the eclectic methodological approaches used and the theoretical or thematic confluence with other disciplines. However, the data obtained allowed us to conclude that this meta-disciplinary nature is not generally associated with the creation of research teams involving authors from diverse disciplinary areas, at least in the four countries analysed. The general statement frequently made in the literature about the interdisciplinary nature of LIS is a somewhat shaky claim that interferes with the scientific policies and evaluation mechanisms used in this field.

- The eclectic nature of the LIS epistemological framework and the confluence of research topics with other areas make it an ideal setting for coauthorship with crossdisciplinary collaboration. However, the data obtained point to possible inbreeding (or self-marginalization) among LIS-affiliated authors. Furthermore, the fact that only $21.5 \%$ of the papers with authors from LIS present cross-disciplinary collaboration makes it important to acknowledge a certain lack of collaborations with other disciplines taken the disciplinary areas two by two: LIS leads in terms of the percentage of bilateral collaborations in only eight of the 12 categories with which it could collaborate, and it does so with small majorities (in six cases the figure is below $40 \%$ and in all cases it is below 50\%), despite the fact that it has the greatest potential to lead the way in terms of the volume of collaborations by producing the highest absolute number of articles with cross-disciplinary collaboration.

LIS-affiliated authors have the lowest share of papers in first-quartile journals and MIS authors the highest, followed by Business, general management and economics, Mathematics, computing and IT, and Experimental sciences and engineering.

- The lack of cross-disciplinary collaboration and the robust "coexistence" of authors from different disciplinary areas under the same Scopus/SJR subject category also have a bibliometric dimension that can affect researchers and institutions whose research results are evaluated according to the impact indicators of the titles in which they publish. Thus, the data obtained show that, although LIS-affiliated authors participate in a greater volume of work than any of the other areas identified, on the whole they publish in titles with a lower bibliometric impact than any of the other areas. In the case of both the Scopus SJR and WoS JCR quartile rankings, the LIS authors were ranked lowest by percentage of output published in first-quartile titles.

- Many serials classified in the SJR and JCR LIS subject category are classified in one (or more) additional category, although the situation is more pronounced in SJR, which has a higher total number of titles in that category and many more cases of classification in multiple categories. This situation gives rise to important differences in the citation patterns received by journals, since the titles that belong to LIS and also to at least 
one additional subject area generally occupy the top positions in impact factor rankings (especially when some of these areas host heavily populated scientific communities in the fields of biomedicine, technology and business information management), thereby replacing more traditional LIS journals from the first quartile.

- Therefore, many journals in specialized niches in LIS barely exceed the third or fourth quartile in these rankings. These data reinforce what other empirical studies have concluded with respect to the need to develop assessment formulas in accordance with the DORA principles and the Leiden Manifesto; for each academic community, the nature of the communication ecosystem and the demographics of the researchers involved should be taken into account. These principles challenge rigid contexts of evaluation based on broad and classic disciplinary areas, which are usually defined externally by the subject classification choices of database producers, and prioritize metrics at article level over metrics at journal level.

Open Access This article is licensed under a Creative Commons Attribution 4.0 International License, which permits use, sharing, adaptation, distribution and reproduction in any medium or format, as long as you give appropriate credit to the original author(s) and the source, provide a link to the Creative Commons licence, and indicate if changes were made. The images or other third party material in this article are included in the article's Creative Commons licence, unless indicated otherwise in a credit line to the material. If material is not included in the article's Creative Commons licence and your intended use is not permitted by statutory regulation or exceeds the permitted use, you will need to obtain permission directly from the copyright holder. To view a copy of this licence, visit http://creativecommons.org/licenses/by/4.0/.

\section{References}

Abramo, G., D’Angelo, C. A., \& Di Costa, F. (2012). Identifying interdisciplinarity through the disciplinary classification of coauthors of scientific publications. Journal of the American Society for Information Science and Technology, 63(11), 2206-2222. https://doi.org/10.1002/asi.22647.

Abrizah, A., Noorhidawati, A., \& Zainab, A. N. (2015). LIS journals categorization in the Journal Citation Report: A stated preference study. Scientometrics, 102(2), 1083-1099. https://doi.org/10.1007/s1119 2-014-1492-3.

Aharony, N. (2012). Library and information science research areas: A content analysis of articles from the top 10 journals 2007-2008. Journal of Librarianship and Information Science, 44(1), 27-35. https:// doi.org/10.1177/0961000611424819.

Apostel, L., Berger, G., Briggs, A., \& Michaud, G. (dir.). (1972). Interdisciplinarity: Problems of Teaching and Research in Universities. Paris: Organisation for Economic Cooperation and Development (OECD).

Ardanuy, J., \& Urbano, C. (2015a). Some research questions to frame a European Union overview on LIS research. III International seminar on LIS education and research (LIS-ER). University of Barcelona, 4-5 June 2015. Barcelona: Universitat de Barcelona. Retrieved February 2, 2020, from http://dipos it.ub.edu/dspace/bitstream/2445/122263/7/Ardanuy\%20Urbano\%20congres\%20bcn.pdf.

Ardanuy, J., \& Urbano, C. (2015b). Una mirada italiana a la colaboración científica europea en Biblioteconomía. Información y Documentación (2010-2014). Biblioteche Oggi Trends, 1(2), 71-82. English version under the title "An Italian perspective of European scientific collaboration in Library and Information Science (2010-2014)". Retrieved February 2, 2020, from http://diposit.ub.edu/dspace/bitst ream/2445/102328/1/656412.pdf.

Ardanuy, J., \& Urbano, C. (2019). The academic-practitioner gap in Spanish library and information science: An analysis of authorship and collaboration in two leading national publications. Journal of Librarianship and Information Science, 51(2), 317-330. https://doi.org/10.1177/0961000617726125.

Åström, F. (2002). Visualizing library and information science concept spaces through keyword and citation based maps and clusters. In H. Bruce, R. Fidel, P. Ingwersen, \& P. Vakkari (Eds.), Emerging frameworks and methods: CoLIS4 (pp. 185-197). Santa Barbara, CA: Libraries Unlimited. 
Åström, F. (2010). The visibility of information science and library science research in bibliometric mapping of the LIS field. Library Quarterly, 80(2), 143-159. https://doi.org/10.1086/651005.

Bates, M. J. (1999). The invisible substrate of information science. Journal of the American Society for Information Science, 50(12), 1043-1050. https://doi.org/10.1002/(SICI)1097-4571(1999)50:12\%3c104 3:AID-ASI1\%3e3.0.CO;2-X.

Best, R. D., \& Kneip, J. (2010). Library schools program and the successful training of academic librarians to meet promotion and tenure requirements in the academy. College and Research Libraries, 71(2), 97-114. https://doi.org/10.5860/0710097.

Bordons, M., Morillo, F., \& Gómez, I. (2004). Analysis of cross-disciplinary research through bibliometric tools. In H. F. Moed, W. Glänzel, \& U. Schmoch (Eds.), Handbook of quantitative science and technology research (pp. 437-456). Dordrecht: Springer. https://doi.org/10.1007/1-4020-2755-9_20.

Borrego, Á., Ardanuy, J., \& Urbano, C. (2018). Librarians as research partners: Their contribution to the scholarly endeavour beyond library and information science. Journal of Academic Librarianship, 44(5), 663-760. https://doi.org/10.1016/j.acalib.2018.07.012.

Buckland, M. K. (1996). Documentation, information science, and library science in the U.S.A. Information Processing and Management, 32(1), 63-76. https://doi.org/10.1016/0306-4573(95)00050-Q.

Buttlar, J. (1999). Information sources in library and information science doctoral research. Library and Information Science Research, 21(2), 227-245. https://doi.org/10.1016/S0740-8188(99)00005-5.

Chang, Y. W. (2018a). Examining interdisciplinarity of library and information science (LIS) based on LIS articles contributed by non-LIS authors. Scientometrics, 116(3), 1589-1613. https://doi.org/10.1007/ s11192-018-2822-7.

Chang, Y. W. (2018b). Exploring the interdisciplinary characteristics of library and information science (LIS) from the perspective of interdisciplinary LIS authors. Library and Information Science Research, 40(2), 125-134. https://doi.org/10.1016/j.lisr.2018.06.004.

Chang, Y. W. (2019). Are articles in library and information science (LIS) journals primarily contributed to by LIS authors? Scientometrics, 121(1), 81-104. https://doi.org/10.1007/s11192-019-03186-w.

Chang, Y. W., \& Huang, M. H. (2012). A study of the evolution of interdisciplinarity in library and information science: Using three bibliometric methods. Journal of the American Society for Information Science and Technology, 63(1), 22-33. https://doi.org/10.1002/asi.21649.

Chavarro, D., Ràfols, I., \& Tang, P. (2017a). To what extent is inclusion in the Web of Science an indicator of journal 'quality'? SSRN network. https://doi.org/10.2139/ssrn.2990653.

Chavarro, D., Tang, P., \& Ràfols, I. (2017b). Why researchers in non-mainstream journals: Training, knowledge bridging and gap-filling. Research Policy, 46(9), 1666-1680. https://doi.org/10.1016/j.respo 1.2017.08.002.

Chen, C., Li, Q., Deng, Z., Chiu, K., \& Wang, P. (2018). The preferences of Chinese LIS journal articles in citing works outside the discipline. Journal of Documentation, 74(1), 99-118. https://doi.org/10.1108/ JD-04-2017-0057.

Chua, A. Y. K., \& Yang, C. C. (2008). The shift towards multi-disciplinarity in information science. Journal of the American Society for Information Science and Technology, 59(13), 2156-2170. https://doi. org/10.1002/asi.20929Cronin.

Cronin, B. (2008). The sociological turn in information science. Journal of Information Science, 34(4), 465-475. https://doi.org/10.1177/0165551508088944.

DORA. (2013). San Francisco Declaration on Research Assessment. Retrieved February 2, 2020, from http://www.ascb.org/dora.

Gómez-Núñez, A. J., Vargas-Quesada, B., \& de Moya-Anegón, F. (2016). Updating the SCImago Journal and Country Rank classification: A new approach using Ward's clustering and alternative combination of citation measures. Journal of the Association for Information Science and Technology, 67(1), 178-190. https://doi.org/10.1002/asi.23370.

Gunawardena, S., Weber, R., \& Agosto, D. (2010). Finding that special someone: Interdisciplinary collaboration in an academic context. Journal of Education for Library and Information Science, 51(4), 210.

Hicks, D., Wouters, P., Waltman, L., de Rijcke, S., \& Rafols, I. (2015). Bibliometrics: The Leiden Manifesto for research metrics. Nature, 520(7548), 429-431. https://doi.org/10.1038/520429a.

Hjørland, B. (2000). Library and information science: Practice, theory, and philosophical basis. Information Processing and Management, 36(3), 501-531. https://doi.org/10.1016/S0306-4573(99)00038-2.

Holbrook, J. B. (2013). What is interdisciplinary communication? Reflections on the very idea of disciplinary integration. Synthese, 190(11), 1865-1879. https://doi.org/10.1007/s11229-012-0179-7.

Holland, G. A. (2008). Information science: An interdisciplinary effort? Journal of Documentation, 64(1), 7-23. https://doi.org/10.1108/00220410810844132. 
Huang, M. H., \& Chang, Y. W. (2011). A study of interdisciplinarity in information science: Using direct citation and co-authorship analysis. Journal of Information Science, 37(4), 369-378. https://doi. org/10.1177/0165551511407141.

Huang, M. H., Shaw, W. C., \& Lin, C. S. (2019). One category, two communities: Subfield differences in "Information Science and Library Science" in Journal Citation Reports. Scientometrics, 119(2), 10591079. https://doi.org/10.1007/s11192-019-03074-3.

Huutoniemi, K., Klein, J. T., Bruun, H., \& Hukkinen, J. (2010). Analyzing interdisciplinarity: Typology and indicators. Research Policy, 39(1), 79-88. https://doi.org/10.1016/j.respol.2009.09.011.

Ingwersen, P. (1992). Information and information science in context. Libri, 42(2), 99-135. https://doi. org/10.1515/libr.1992.42.2.99.

Jacobs, J. A., \& Frickel, S. (2009). Interdisciplinarity: A critical assessment. Annual Review of Sociology, 35(1), 43-65. https://doi.org/10.1146/annurev-soc-070308-115954.

Jamali, H. R., Azadi-Ahmadabadi, G., \& Asadi, S. (2018). Interdisciplinary relations of converging technologies: Nano-Bio-Info-Cogno (NBIC). Scientometrics, 116(2), 1055-1073. https://doi. org/10.1007/s11192-018-2776-9.

Janssens, F., Zhang, L., De Moor, B., \& Glänzel, W. (2009). Hybrid clustering for validation and improvement of subject-classification schemes. Information Processing and Management, 45(6), 683-702. https://doi.org/10.1016/j.ipm.2009.06.003.

Jokić, M. (2020). Productivity, visibility, authorship, and collaboration in library and information science journals: Central and Eastern European authors. Scientometrics, 122(2), 1189-1219. https:// doi.org/10.1007/s11192-019-03308-4.

Klein, J. T. (1990). Interdisciplinarity: History, theory, and practice. Detroit: Wayne State University Press.

Klein, J. T. (2017). Typologies of interdisciplinarity: The boundary work of definition. In R. Frodeman (Ed.), The Oxford handbook of interdisciplinarity (2nd ed., pp. 21-34). Oxford: Oxford University Press.

Levitt, J. M., \& Thelwall, M. (2009). The most highly cited library and information science articles: Interdisciplinarity, first authors and citation patterns. Scientometrics, 78(1), 45-67. https://doi. org/10.1007/s11192-007-1927-1.

Leydesdorff, L., \& Bornmann, L. (2015). The operationalization of "fields" as WoS subject categories (WCs) in evaluative bibliometrics: The cases of "libraryand information science" and "science and technology studies". Journal of the Association for Information Science and Technology, 67(3), 707-714. https://doi.org/10.1002/asi.23408.

López-Illescas, C., Noyons, E., Visser, M., de Moya-Anegón, F., \& Moed, H. (2009). Expansion of scientific journal categories using reference analysis: How can it be done and does it make a difference? Scientometrics, 79(3), 473-490. https://doi.org/10.1007/s11192-007-1975-6.

Meyer, T., \& Spencer, J. (1996). A citation analysis study of the library science: Who cites librarians? College and Research Libraries, 57(1), 23-33. https://doi.org/10.5860/crl_57_01_23.

Nakano, N., Martínez-Ávila, D., Vicentini Jorente, M. J., \& Cantisani, M. (2018). Information design, information science, and knowledge organization: A domain analysis from the perspective of complexity. Scire, 24(1), 67-75.

Odell, J., \& Gabbard, R. (2008). The interdisciplinary influence of library and information science 1996-2004: A journal-to-journal citation analysis. College and Research Libraries, 69(6), 546564. https://doi.org/10.5860/crl.69.6.546.

Ollé, C., López-Borrull, A., \& Abadal, E. (2016). The challenges facing library and information science journals: Editors' opinions. Learned Publishing, 29(2), 89-94. https://doi.org/10.1002/leap.1016.

Porter, A. L., \& Chubin, D. E. (1985). An indicator of cross-disciplinary research. Scientometrics, 8(34), 161-176. https://doi.org/10.1007/BF02016934.

Prebor, G. (2010). Analysis of the interdisciplinary nature of library and information science. Journal of Librarianship and Information Science, 42(4), 256-267. https://doi.org/10.1177/096100061038082 0 .

Qin, J., Lancaster, F. W., \& Allen, B. (1997). Types and levels of collaboration in interdisciplinary research in the sciences. Journal of the American Society for Information Science, 48(10), 893916. https://doi.org/10.1002/(SICI)1097-4571(199710)48:10\%3c893:AID-ASI5\%3e3.0.CO;2-X.

Ràfols, I., Molas-Gallart, J., Chavarro, D. A., \& Robinson-Garcia, N. (2016). On the dominance of quantitative evaluation in 'peripheral' countries: Auditing research with technologies of distance. SSRN network. https://doi.org/10.2139/ssrn.2818335.

Saracevic, T. (1995). Interdisciplinary nature of information science. Ciência da informação, 24(1), 36-41.

Saracevic, T. (1999). Information science. Journal of the American Society for Information Science, 50(12), 1051-1063. https://doi.org/10.1002/(SICI)1097-4571(1999)50:12\%3c1051:AID-ASI2\%3e3.0.CO;2-Z. 
Schummer, J. (2004). Multidisciplinarity, interdisciplinarity, and patterns of research collaboration in nanoscience and nanotechnology. Scientometrics, 59(3), 425-465. https://doi.org/10.1023/ B:SCIE.0000018542.71314.38.

Shera, J. H. (1968). Of librarianship, documentation and information science. UNESCO Bulletin for Libraries, 22(2), 58-65.

So, C. Y. K. (1988). Citation patterns of core communication journals: An assessment of the developmental status of communication. Human Communication Research, 15(2), 236-255. https://doi. org/10.1111/j.1468-2958.1988.tb00183.x.

Sugimoto, C. R., Ni, C., Russell, T. G., \& Bychowski, B. (2011). Academic genealogy as an indicator of interdisciplinarity: An examination of dissertation networks in library and information science. Journal of the American Society for Information Science and Technology, 62(9), 1808-1828. https ://doi.org/10.1002/asi.21568.

Tang, R. (2004). Evolution of the interdisciplinary characteristics of information and library science. Proceedings of the American Society for Information Science and Technology, 41(1), 54-63. https://doi. org/10.1002/meet.1450410107.

Thijs, B., Zhang, L., \& Glänzel, W. (2015). Bibliographic coupling and hierarchical clustering for the validation and improvement of subject-classification schemes. Scientometrics, 105(3), 1453-1467. https:// doi.org/10.1007/s11192-015-1641-3.

Tseng, Y. H., \& Tsay, M. Y. (2013). Journal clustering of library and information science for subfield delineation using the bibliometric analysis toolkit: CATAR. Scientometrics, 95(2), 503-528. https://doi. org/10.1007/s11192-013-0964-1.

Urbano, C., Seguí, R., \& Borrego, Á. (2005). Clasificar el conocimiento para evaluar la generación de conocimiento: clasificaciones y evaluación de la investigación en ciencias humanas y sociales. Congreso del Capítulo Español de ISKO (7: 2005: BARCELONA). La dimensió humana de l'organització del coneixement (pp. 597-612). Retrieved February 2, 2020, from http://dialnet.unirioja.es/servlet/artic ulo?codigo $=2969312$.

Vakkari, P. (1994). Library and information science: Its content and scope. Advances in Librarianship, 18, 1-55. https://doi.org/10.1108/S0065-2830(1994)0000018003.

Van Eck, N. J., Waltman, L., Van Raan, A. F. J., Klautz, R. J. M., \& Peul, W. C. (2013). Citation analysis may severely underestimate the impact of clinical research as compared to basic research. PLOS ONE, 8(4), e62395. https://doi.org/10.1371/journal.pone.0062395.

Vessuri, H., Guédon, J. C., \& Cetto, A. M. (2014). Excellence or quality? Impact of the current competition regime on science and scientific publishing in Latin America and its implications for development. Current Sociology, 62(5), 647-665. https://doi.org/10.1177/0011392113512839.

Zhang, L., Janssens, F., Liang, L., \& Glänzel, W. (2010). Journal cross-citation analysis for validation and improvement of journal-based subject classification in bibliometric research. Scientometrics, 82(3), 687-706. https://doi.org/10.1007/s11192-010-0180-1. 